\title{
Extensive calcification of the interventricular septum with caseous cavity deriving from stenotic aortic valve
}

\section{Branislav Bezáka , Panagiotis Artemioua , Juraj Grebáčc , Dávid Kocanº, Michal Hulmana}

\author{
a Clinic of Cardiac Surgery, Medical Faculty of the Comenius University, National Institute of Cardiovascular Diseases, \\ Bratislava, Slovakia \\ ${ }^{b}$ Department of Radiology, National Institute of Cardiovascular Diseases, Bratislava, Slovakia
}

ARTICLE INFO

Article history:

Submitted: 27. 4. 2021

Revised: 24. 5. 2021

Accepted: 25. 5. 2021

Available online: 1. 12. 2021

\author{
Klíčová slova: \\ Bikuspidální aortální chlopeň \\ Kalcifikace interventrikulárního septa \\ Stenóza aortální chlopně \\ Výpočetní tomografie
}

Keywords:

Aortic valve stenosis

Bicuspid aortic valve

Computed tomography

Interventricular septum calcification 34-year-old patient, in a follow-up since childhood for bicuspid aortic valve was referred to our department due to severe symptomatic aortic valve stenosis. Electrocardiography was normal. Transthoracic and transesophageal echocardiography with a 3D option showed a heavily calcified aortic valve with severe stenosis. The calcifications extended towards the left ventricular outflow tract and interventricular septum, forming a $12 \mathrm{~mm}$ prominence below the aortic valve without any subvalvular stenosis (Fig. 1A).

Computed tomography (CT) scan of the thoracic aorta revealed extensive coarse calcifications in the aortic valve extending into the left ventricular outflow tract and into the basal and middle parts of the interventricular septum. The appearance of the calcifications in the mid septal segment was suggestive of a caseous etiology which is rather unusual in this location. Due to the reason that the caseous calcification was resembling a cavity opacified with the contrast agent, an unenhanced CT scan (Fig. 1B) was performed where the diagnosis of the caseous calcification was confirmed.

This highly uncommon form of calcification can also occur in younger patients. ${ }^{1}$

The patient underwent a successful aortic valve replacement procedure. An informed consent and institutional review board permission were obtained to present this image.

\section{Conflict of interest and funding}

The authors declare no funding and no conflict of interest.

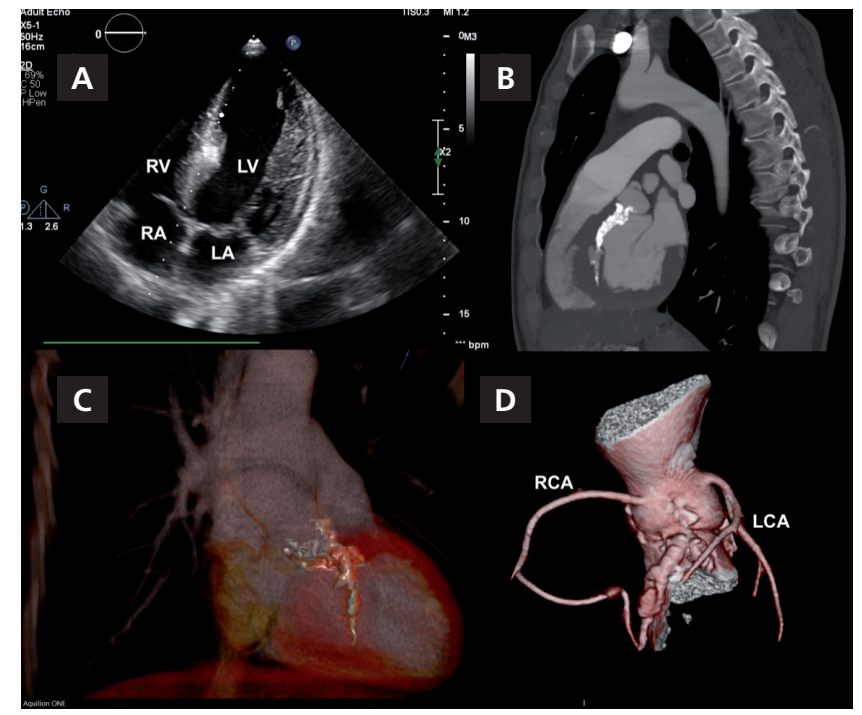

Fig. 1 - (A) Transthoracic echocardiography. (B) CTA of the aorta. (C) 3D VRT showing the distribution of the calcifications in the aortic valve and the interventricular septum. (D) VRT showing the relation to the coronary arteries. CTA - computed tomography angiography; LA - left atrium; LCA - left coronary artery; LV - left ventricle; RA - right atrium; RCA - right coronary artery; RV - right ventricle; VRT - volume rendering technique.

\section{References}

1. Tomaszuk-Kazberuk A, Lukasiewicz A, Sobkowicz B, Musial WJ. Giant calcifications in the interventricular septum deriving from the aortic. stenosis. Eur Heart J Cardiovasc Imaging 2012:13:365.

Address: MUDr. Panagiotis Artemiou, PhD., Clinic of Cardiac Surgery Medical Faculty of the Comenius University, National Institute of Cardiovascular Diseases, Pod Krásnou hôrkou 1, 83348 Bratislava 37, Slovakia, e-mail: panayiotisartemiou@yahoo.com (c) 2021, ČKS 